\title{
Single Incision Laparoscopic Surgery Development at the Hospital Clinic: Our 4-Year Experience
}

\author{
Josep Martí, Oscar Vidal*, Mauro Valentini, Cesar Ginestà, Juan José Espert, \\ Miss Yolanda Rodriguez, Guerson Benarroch, Juan Carlos García-Valdecasas \\ General Surgery and Emergency Unit, Department of General and Digestive Surgery, Digestive Diseases and \\ Metabolism Institute, Hospital Clínici Provincial, Universitat de Barcelona, IDIBAPS, Barcelona, Spain \\ Email: ${ }^{*}$ ovidal@clinic.ub.es
}

Received 22 December 2014; accepted 5 January 2015; published 14 January 2015

Copyright (C 2015 by authors and Scientific Research Publishing Inc.

This work is licensed under the Creative Commons Attribution International License (CC BY). http://creativecommons.org/licenses/by/4.0/

(c) (7) Open Access

\begin{abstract}
Background: Single incision laparoscopic surgery (SILS) has still not replaced conventional laparoscopic surgery in many centers because of its special instruments requirements and training needs. In our Institution we introduced SILS procedures in a procedural stepwise manner, with progression to more difficult procedures only allowed if complete proficiency in low-complexity ones is achieved. Methods: We studied the evolution of performed SILS procedures in our Institution from the beginning of the program (mainly appendectomies, cholecystectomies, left adrenalectomies) and the results from these techniques. Results: Among 328 SILS procedures there were 148 appendectomies ( 24 by suprapubic access), 141 cholecystectomies, 32 left adrenalectomies, 6 diagnostic laparoscopies and 1 resection of Meckel's diverticulum. The majority of appendectomies accounted for non-perforated appendicitis cases and there were no significant differences between transumbilical and suprapubic access groups. In cholecystectomies the majority of patients were elective cases and oral intake could be resumed within the 6 postoperative hours. In left adrenalectomies no conversion to open surgery was required and there were no intraoperative or postoperative complications. Conclusions: Procedural stepwise approach in SILS is a valid, feasible and safe option that can be applied at any institution starting a SILS program.
\end{abstract}

\section{Keywords}

Adrenal, Appendix, Cholecystectomy, Training/Courses, Education

\section{Introduction}

Laparoscopic surgery has experienced a fast development because of its advantages when compared to tradi-

"Corresponding author. 
tionally open procedures in many organs [1]-[7]. The majority of the advances have been directed to reduce the amount of non-visceral injury to the patient at a minimum because surgical and oncological actions over affected organs should remain unchanged regardless of the use of open or laparoscopic techniques. Single-incision laparoscopic surgery (SILS) has emerged as the logical evolution in minimally invasive surgery by decreasing the amount of parietal injury to a minimal unique incision. However, SILS has still not replaced conventional laparoscopic surgery in many centers because of its special instruments requirements and training needs [8].

SILS procedures can be performed using conventional or articulated instruments [9]. Conventional instruments are an easy and cheap alternative to start with SILS technique but the use of these instruments is initially difficult because narrow working angles difficult dissection movements inside the abdomen. Luckily, some authors have proposed several solutions to safely face the difficulties arising during the learning bridge from multiport laparoscopic surgery to SILS [10]. On the other side, the majority of authors have started performing SILS procedures using specific articulated instruments and they have based their skills acquisition on the simultaneous performance of many different procedures [11]. However, this strategy needs large amounts of patients for procedural establishment purposes and can be also rather difficult to apply in small centers where SILS is to be introduced.

In our Institution we started performing SILS procedures with specific articulated instruments and we increased surgical complexity in a procedural stepwise manner. In this approach, the surgeon can only progress towards more difficult procedures only if he achieves complete proficiency in low-complexity ones to increase patient safety. However, studies about the results of introducing SILS by this logical, simple and attractive strategy are lacking, and for this reason we aimed to review the surgical results and the safety of introducing this procedural stepwise approach in our Institution.

\section{Materials and Methods}

We started our SILS program in December 2008 with the performance of SILS appendectomies [12]. At the beginning, only a team of 3 surgeons with a special interest on this technique (O.V., M.V. and C.G.) performed the cases. As these surgeons gained enough experience with this procedure, other members of the Surgery Department (either attendings or residents) were assisting and then performing some of these initial procedures. Soon after becoming proficient in SILS appendectomies we started to perform SILS cholecystectomies on the same basis (first the 3 surgeons of the SILS team and later the other members of the department). Finally, we started to perform some bowel (Meckel's diverticulum resection), colorectal (drain placement for acute diverticulitis) and left adrenal procedures.

\subsection{Operative Techniques}

The technical details of SILS appendectomy in our Institution mainly consist in using a $2.5 \mathrm{~cm}$ incision in the left superior umbilical zone through the linea alba where a 3 ports device (SILS KIT 2, Covidien, Norwalk, CT) is introduced and both conventional and flexible instruments are used to remove the appendix [12]. To achieve better cosmetic results, we later introduced the suprapubic access, which mainly consists in moving the same incision at the intersection between the infraumbilical midline and the pubic hairline [13]. SILS cholecystectomies are performed through a right superior umbilical incision with similar 3 ports access than appendectomy but with flexible instruments only and following the same steps than in conventional laparoscopic surgery (Calot triangle exposure and dissection followed by dissection from the liver bed and extraction through the single incision with a plastic bag) [14]. After showing proficiency with elective cholecystectomies we progressed to include patients with acute cholecystitis and we also started to perform them on a day surgery basis [15]. All day surgery cholecystectomies cases were elective and surgery was scheduled in the early morning to enable a safe observation period. For left adrenalectomies [16] we decided to adopt the technical principles described by Zacharias [17]. Briefly, we start by incising Toldt's line from the splenic flexure to the sigmoid junction to medially reflect the left colon. After it, we cut the phrenocolic and lienorenal ligaments and the splenic attachments to the abdominal side wall and the diaphragm to obtain a good vision of the upper pole of the left kidney. We clip and divide the adrenal vein, we free the gland from its medial and lateral attachments and finally we extract it through the single incision with a plastic bag.

\subsection{Postoperative Care}

All patients remained in the post anesthesia care unit for a minimum of 2 hours before being transferred to the 
surgical ward. Oral intake was progressively resumed at least after the 6 postoperative hours depending on the clinical case and all patients were encouraged for early ambulation. The wound was inspected every morning during the hospital stay and 7 days after surgery at the outpatient clinic. In day surgery cases the wound was inspected before patient's discharge and 7 days after surgery at the outpatient clinic as per protocol [15].

\subsection{Study Design}

Following local Institutional Review Board approval, we obtained the clinical data from the patients from the General Surgery Department prospective SILS database. We performed a descriptive retrospective analysis of the preoperative (demographical, anesthetic risk, diagnosis), intraoperative (procedure, length of surgery, need for conversion or port addition, drain placement, other intraoperative incidences, length of incision) and postoperative characteristics (need for reoperation, complications, length of stay, pain (by Visual Analgesic Scale) and post-discharge complications).

\subsection{Statistical Analysis}

Categorical variables were compared using the chi-square or Fisher's exact test. Continuous variables were expressed as the mean \pm standard deviation and compared using Student's $t$ and ANOVA tests. When a normal distribution was not present, continuous variables were expressed as the median and the range and compared using the Mann-Whitney U test. All statistical analyses were performed with the "Statistical Package for the Social Sciences” version 18.0 for Windows (SPSS, Chicago, IL).

\section{Results}

From December 2008 to April 2012 we performed 328 SILS procedures. There were 148 appendectomies, 141 cholecystectomies, 32 left adrenalectomies, 6 diagnostic laparoscopies and 1 resection of Meckel's diverticulum. The distribution of main procedures over time is depicted in Figure 1.

There were 124 appendectomies by transumbilical access and 24 by suprapubic access. The majority of patients (70\%) were men and non-perforated appendicitis accounted for the majority of cases (64\%). Incision length was $2.7 \pm 0.8 \mathrm{~cm}$ and mean operative time was $35 \pm 7$ minutes. In 8 cases (5.4\%) an additional port was needed to complete the operation, all in transumbilical access cases. There was only $1(0.6 \%)$ intraoperative

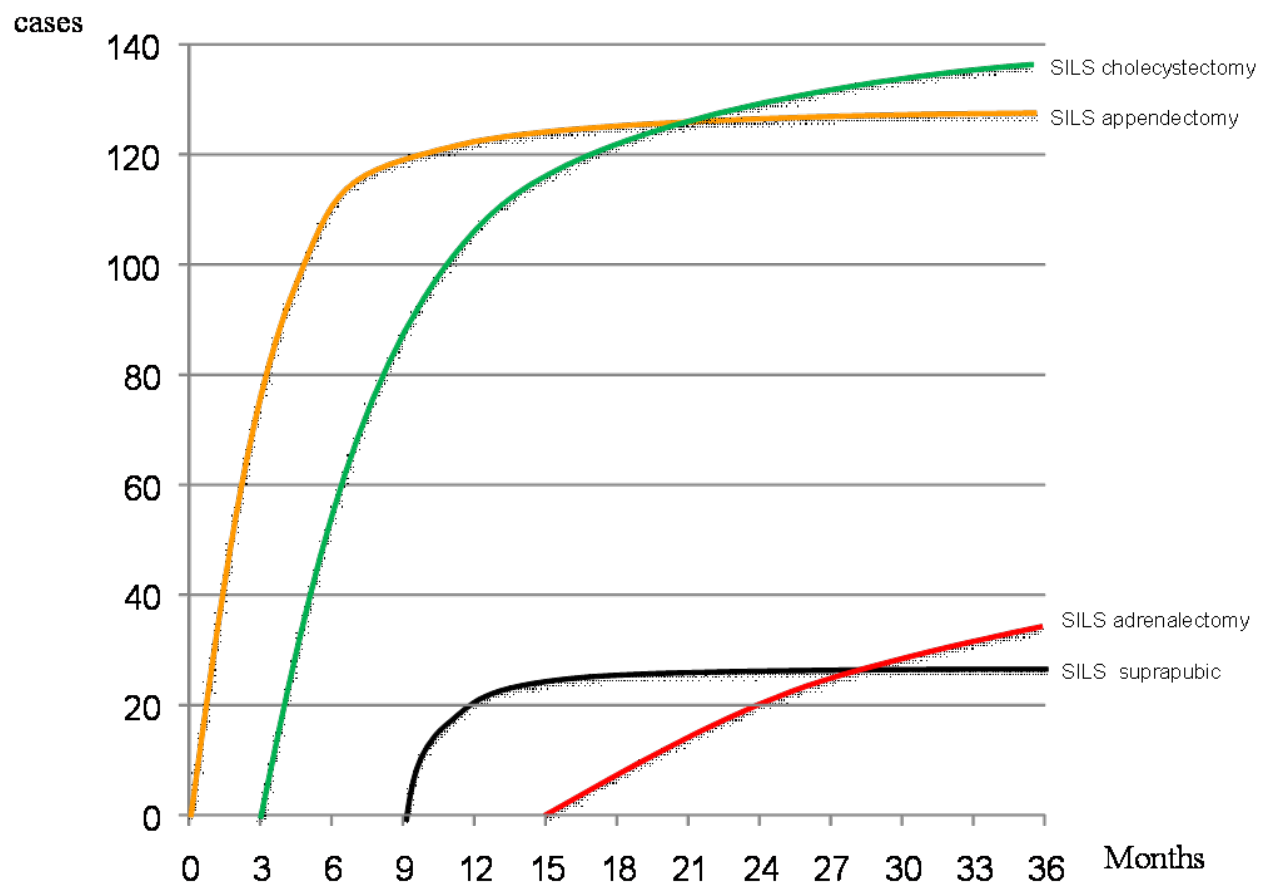

Figure 1. Distribution of SILS procedures over time. 
complication (bleeding). A drain was used in 18 (12\%) cases. Median (range) VAS for postoperative pain intensity was $2(1-4)$ and 4 cases $(2.7 \%)$ had postoperative complications (1 wound infection and 3 hematomas, all in transumbilical access cases). Almost all patients resumed oral intake within the first 24 hours after operation and mean hospital stay was $2.1 \pm 0.7$ days. Only 2 patients (1.35\%) presented with incisional hernia after a median follow-up longer than 40 months. There were no significant differences between transumbilical and suprapubic access groups for the majority of study variables (Table 1 ).

About cholecystectomies, there were 137 (97\%) elective cases and 4 (3\%) emergency cases because of acute cholecystitis. Women accounted for the majority of patients (68\%) and mean age was $62 \pm 2$ years. Incision length was $2.7 \pm 3 \mathrm{~cm}$ and operative time was $62 \pm 7$ minutes. In 6 cases an additional port was needed to complete the operation. We used a drain in 2 elective cases $(1.4 \%)$ and in all emergency cases. There were 3 intraoperative incidences (incomplete cystic duct clipping) and 6 (4\%) postoperative complications (2 wound infection and 4 umbilical hematomas), all of them presenting in elective patients. The median (range) VAS for postoperative pain intensity was $3(1-7)$. Oral intake could be resumed within the 6 postoperative hours in $98 \%$ of elective cases and took longer in all the emergency cases. Hospital stay in elective cases was $1(1-2)$ day while in emergency cases was 4 (3 - 9). None of the patients had incisional hernia after a median follow-up longer than 36 months (Table 2).

The majority of patients undergoing left adrenalectomies were female (75\%) and mean age was $63 \pm 3$ years. Incision length was $3.5 \pm 0.5 \mathrm{~cm}$ and operative time was $95 \pm 5$ minutes. In 1 case an additional port for holding the kidney was needed to complete the operation. Operation was successfully completed in all patients and no conversion to open surgery was required. There were no intraoperative or postoperative complications. Median (range) VAS for postoperative pain intensity was 3 (2 - 6). Most patients resumed oral intake within the first 24 hours after operation and length of hospital stay was $3 \pm 1$ days. None of patients developed incisional hernia after a median follow-up longer than 24 months (Table 3).

Table 1. Characteristics of SILS appendectomies.

\begin{tabular}{|c|c|c|c|}
\hline & Overall (n = 148) & Transumbilical (n = 124) & Suprapubic $(n=24)$ \\
\hline Age (years) & $32 \pm 3(19-52)$ & $29 \pm 3(19-52)$ & $35 \pm 3(19-42)$ \\
\hline $\operatorname{Sex}(M / F)$ & 103 (70\%)/45 (30\%) & $84(68 \%) / 40(32 \%)$ & $19(79 \%) / 5(21 \%)$ \\
\hline ASA risk (I-II/III-IV) & $(100 \% / 0 \%)$ & $(100 \% / 0 \%)$ & $(100 \% / 0 \%)$ \\
\hline Perforated appendicitis & $54(36 \%)$ & $47(38 \%)$ & $7(29 \%)$ \\
\hline Need for additional ports & $8(5.4 \%)$ & $8(6.5 \%)$ & $0(0 \%)$ \\
\hline Conversion to open surgery & 0 & 0 & 0 \\
\hline Drain placement & $18(12 \%)$ & $12(9.7 \%)$ & $6(25 \%)$ \\
\hline Intraoperative incidences & $1(0.6 \%)$ & $1(0.8 \%)$ & $0(0 \%)$ \\
\hline Length of surgery (min) & $35 \pm 7(19-81)$ & $30 \pm 7(19-65)$ & $40 \pm 7(25-81)$ \\
\hline Incision length (cm) & $2.7 \pm 0.8(2-3.9)$ & $3 \pm 0.9(2-3.9)$ & $2.4 \pm 0.7(2.2-2.9)$ \\
\hline Need for reoperation & 0 & 0 & 0 \\
\hline Postoperative complications & $4(2.7 \%)$ & $4(3 \%)$ & $0(0 \%)$ \\
\hline First hour pain (VAS) & $2(1-4)$ & $2(1-3)$ & $2(1-4)$ \\
\hline \multicolumn{4}{|l|}{ Oral intake starting (hours) } \\
\hline$<24$ & $146(98.6 \%)$ & $122(98.4 \%)$ & $24(100 \%)$ \\
\hline$>24$ & $2(1 \%)$ & $2(1.6 \%)$ & 0 \\
\hline Length of stay (days) & $2.1 \pm 0.7(2-4)$ & $2.2 \pm 1(2-4)$ & $2 \pm 0.5(2-4)$ \\
\hline Post-discharge complications & $1(0.6 \%)$ & $0(0 \%)$ & $1(4.2 \%)$ \\
\hline Incisional hernia & 2 (1.35\%) & $2(1.6 \%)$ & 0 \\
\hline
\end{tabular}


Table 2. Characteristics of SILS cholecystectomies.

\begin{tabular}{cccc}
\hline & Overall $(\mathrm{n}=141)$ & Elective $(\mathrm{n}=137)$ & Emergent $(\mathrm{n}=4)$ \\
\hline Age (years) & $62 \pm 2(29-89)$ & $56 \pm 2(29-70)$ & $68 \pm 3(59-89)$ \\
Sex (M/F) & $45(32 \%) / 96(68 \%)$ & $45(33 \%) / 92(67 \%)$ & $0(0 \%) / 4(100 \%)$ \\
ASA risk & & & $1(25 \%)$ \\
I-II/ & $138(98 \%)$ & $137(100 \%)$ & $3(75 \%)$ \\
III-IV & $3(2 \%)$ & $0(0 \%)$ & $3(75 \%)$ \\
Need for additional ports & $6(4.2 \%)$ & $3(2 \%)$ & $1(25 \%)$ \\
Need for conversion to open surgery & $1(0.7 \%)$ & $0(0 \%)$ & $4(100 \%)$ \\
Need for drain placement & $6(4.2 \%)$ & $2(1.4 \%)$ & $0(0 \%)$ \\
Intraoperative incidences & $3(2 \%)$ & $3(2 \%)$ & $75 \pm 8(60-100)$ \\
Length of surgery (min) & $62 \pm 7(25-100)$ & $50 \pm 3(25-95)$ & $2.6 \pm 4(2.4-3)$ \\
Incision length (cm) & $2.7 \pm 3(2-3.3)$ & $0.0 .2(2-3.3)$ & 0 \\
Need for reoperation & 0 & $5(3.6 \%)$ & $1(25 \%)$ \\
Postoperative complications & $6(4.2 \%)$ & $3(1-5)$ & $4(3-7)$ \\
First hour pain (VAS) & $3(1-7)$ & & $0(0 \%)$ \\
Oral intake starting (hours) & $134(95 \%)$ & $3(2 \%)$ & $4(100 \%)$ \\
$<6$ & $7(5 \%)$ & $1 \pm 1(2-4)$ & $4 \pm 1.5(3-9)$ \\
>6 & $3 \pm 1(2-9)$ & $0(0 \%)$ & $1(25 \%)$ \\
Length of stay (days) & $1(0.7 \%)$ & 0 & 0 \\
Post-discharge complications & 0 & & $0.9 \%)$ \\
Incisional hernia & & $134 \%)$ & \\
\hline
\end{tabular}

Table 3. Characteristics of SILS left adrenalectomies $(n=32)$.

\begin{tabular}{|c|c|}
\hline Age (years) & $63 \pm 3(43-78)$ \\
\hline $\operatorname{Sex}(M / F)$ & $8(25 \%) / 24(75 \%)$ \\
\hline ASA risk (I-II/III-IV) & $50 \% / 50 \%$ \\
\hline Need for additional ports & $1(3 \%)$ \\
\hline Conversion to open surgery & 0 \\
\hline Need for drain placement & 0 \\
\hline Intraoperative incidences & 0 \\
\hline Length of surgery (min) & $95 \pm 5(75-125)$ \\
\hline Incision length (cm) & $3.5 \pm 0.5(3-4.2)$ \\
\hline Need for reoperation & 0 \\
\hline Postoperative complications & 0 \\
\hline First hour pain (VAS) & $3(2-6)$ \\
\hline \multicolumn{2}{|l|}{ Oral intake starting } \\
\hline$<24$ hours & $31(97 \%)$ \\
\hline$>24$ hours & $1(3 \%)$ \\
\hline Length of stay (days) & $3 \pm 1(2-4)$ \\
\hline Post-discharge complications & 0 \\
\hline Tumor size (cm) & $3(1.5-4)$ \\
\hline \multicolumn{2}{|l|}{ Pathologic diagnosis } \\
\hline Conn's syndrome & $8(25 \%)$ \\
\hline Cushing's syndrome & $6(19 \%)$ \\
\hline Non-functioning tumor & $18(56 \%)$ \\
\hline Blood loss $<10 \mathrm{ml}$ & $32(100 \%)$ \\
\hline Incisional hernia & 0 \\
\hline
\end{tabular}




\section{Discussion}

SILS has emerged as the logical evolving procedure from conventional laparoscopic surgery mainly because it decreases the amount of parietal injury to a minimal unique incision. Although attractive, in several centers SILS has still not replaced conventional laparoscopic surgery because of its specific instruments and training needs [8]. However, a general introductory approach still does not exist and several options involving the use of conventional and articulated instruments [9] have been described, each one with its own advantages and drawbacks [10] [11]. In our Institution we adopted from the very beginning the strategy of performing SILS procedures and its subsequent learning curve by increasing the surgical complexity in a procedural stepwise manner. Although logical, the progression to more difficult procedures only when the surgeon is completely proficient in low-complexity ones has never been formally described nor tested for procedure results and safety.

New techniques must have similar or better results than previously used techniques before being definitively adopted and replacing the old ones [8]. Patients in our study showed excellent results in terms of postoperative complications, pain and length of stay. About postoperative pain, all procedures positively compared with wellanalyzed series describing these procedures performed by conventional laparoscopy [1]. Also, SILS appendectomies and cholecystectomies had a similar length of stay than previously published laparoscopic results [2] [3]. For these reasons, we believe that progression from appendectomies to cholecystectomies and then to more complex procedures like left adrenalectomies in a procedural stepwise manner should be recommended to obtain good intraoperative and postoperative outcomes when introducing a SILS program at any institution.

One of the main critical issues when introducing a new surgical technique is patient safety, which can be elucidated from the need to convert to a conventional laparoscopic or open procedure because of intraoperative problems [1]. The majority of patients in our study completed their procedure without the need of adding supplemental ports or converting to open surgery, showing that SILS introduction in a procedural stepwise manner is associated with a low rate of intraoperative problems. We believe that these results show that the procedural stepwise approach can help to safely introduce SILS at any institution because appendectomies and elective or urgent cholecystectomies are very common surgical procedures in any center. We suggest that they can be easily used as initial procedures for SILS introduction and then depending on the institution case mix a certain direction towards specific procedures (colorectal, adrenal) can be taken. However, our study design cannot define the needed amount of patients to progress to the next procedure and for this reason we recommend further studies addressing this important issue.

As a conclusion, our study shows that the procedural stepwise approach is a valid, feasible and safe option that can be applied at any institution starting a SILS program. Although the amount of needed patients for progressing to the next procedure cannot be clearly defined by our study, further trials along with a continuous surgical results monitoring is crucial to decide the moment when progression to more difficult procedures should be allowed.

\section{Disclosures}

Josep Martí, MD, PhD, Oscar Vidal, MD, PhD, Mauro Valentini, PhD, MD, Cesar Ginestà, MD, Juan José Espert, MD, PhD, Guerson Benarroch, MD and Juan Carlos García-Valdecasas, MD, PhD have no conflicts of interest or financial ties to disclose.

\section{Funding Information}

The authors do not have any funding information to disclose.

\section{References}

[1] Tiwari, M.M., Reynoso, J.F., High, R., Tsang, A.W. and Oleynikov, D. (2011) Safety, Efficacy, and Cost-Effectiveness of Common Laparoscopic Procedures. Surgical Endoscopy, 25, 1127-1135. http://dx.doi.org/10.1007/s00464-010-1328-z

[2] Vettoretto, N. and Agresta, F. (2011) A Brief Review of Laparoscopic Appendectomy: The Issues and the Evidence. Techniques in Coloproctology, 15, 1-6. http://dx.doi.org/10.1007/s10151-010-0656-2

[3] Keus, F., Gooszen, H.G. and van Laarhoven, C.J. (2010) Open, Small-Incision, or Laparoscopic Cholecystectomy for Patients with Symptomatic Cholecystolithiasis. An Overview of Cochrane Hepato-Biliary Group Reviews. Cochrane 
Database of Systematic Reviews, 20, CD008318.

[4] Aly, E.H. (2009) Laparoscopic Colorectal Surgery: Summary of the Current Evidence. Annals of the Royal College of Surgeons of England, 91, 541-544. http://dx.doi.org/10.1308/003588409X464757

[5] Feldman, L.S. (2011) Laparoscopic Splenectomy: Standardized Approach. World Journal of Surgery, 35, $1487-1495$. http://dx.doi.org/10.1007/s00268-011-1059-x

[6] Mazzaglia, P.J. and Vezeridis, M.P. (2010) Laparoscopic Adrenalectomy: Balancing the Operative Indications with the Technical Advances. Journal of Surgical Oncology, 101, 739-744.

[7] Edwin, B., Nordin, A. and Kazaryan, A.M. (2011) Laparoscopic Liver Surgery: New Frontiers. Scandinavian Journal of Surgery, 100, 54-65.

[8] Tsai, A.Y. and Selzer, D.J. (2010) Single-Port Laparoscopic Surgery. Advances in Surgery, 44, 1-27. http://dx.doi.org/10.1016/j.yasu.2010.05.017

[9] Tang, B., Hou, S. and Cuschieri, S.A. (2012) Ergonomics of and Technologies for Single-Port Laparoscopic Surgery. Minimally Invasive Therapy \& Allied Technologies, 21, 46-54. http://dx.doi.org/10.3109/13645706.2011.627924

[10] Podolsky, E.R. and Curcillo 2nd, P.G. (2010) Single Port Access (SPA) Surgery-A 24-Month Experience. Journal of Gastrointestinal Surgery, 14, 759-767. http://dx.doi.org/10.1007/s11605-009-1081-6

[11] Khandelwal, S., Wright, A.S., Figueredo, E., Pellegrini, C.A. and Oelschlager, B.K. (2011) Single-Incision Laparoscopy: Training, Techniques, and Safe Introduction to Clinical Practice. Journal of Laparoendoscopic \& Advanced Surgical Techniques A, 21, 687-693. http://dx.doi.org/10.1089/lap.2011.0238

[12] Vidal, O., Valentini, M., Ginestà, C., Benarroch, G. and García-Valdecasas, J.C. (2009) Single Incision Laparoscopic Appendectomy (SILS): Initial Experience. Cirugía Española, 85, 317-319. http://dx.doi.org/10.1016/j.ciresp.2009.01.003

[13] Vidal, O., Valentini, M., Ginestà, C., Martí, J., Espert, J.J., Benarroch, G. and García-Valdecasas, J.C. (2010) Laparoendoscopic Single-Site Surgery Appendectomy. Surgical Endoscopy, 24, 686-691. http://dx.doi.org/10.1007/s00464-009-0661-6

[14] Vidal, O., Valentini, M., Ginestà, C., Espert, J.J., Martinez, A., Benarroch, G., Anglada, M.T. and García-Valdecasas, J.C. (2011) Single-Incision Versus Standard Laparoscopic Cholecystectomy: Comparison of Surgical Outcomes from a Single Institution. Journal of Laparoendoscopic \& Advanced Surgical Techniques A, 21, 683-686. http://dx.doi.org/10.1089/lap.2011.0047

[15] Vidal, O., Pavel, M., Valentini, M., Ginesta, C., Martí, J., Espert, J.J., Benarroch, G. and García-Valdecasas, J.C. (2012) Single-Incision Laparoscopic Cholecystectomy for Day Surgery Procedure: Are We Prepared? The American Surgeon, 78, 436-439.

[16] Vidal, O., Astudillo, E., Valentini, M., Ginestà, C., García-Valdecasas, J.C. and Fernandez-Cruz, L. (2012) Single-Incision Transperitoneal Laparoscopic Left Adrenalectomy. World Journal of Surgery, 36, 1395-1399. http://dx.doi.org/10.1007/s00268-012-1555-7

[17] Zacharias, M., Haese, A., Jurczok, A., Stolzenburg, J.U. and Fornara, P. (2006) Transperitoneal Laparoscopic Adrenalectomy: Outline of the Preoperative Management, Surgical Approach, and Outcome. European Urology, 49, 448-459. http://dx.doi.org/10.1016/j.eururo.2006.01.014 
Scientific Research Publishing (SCIRP) is one of the largest Open Access journal publishers. It is currently publishing more than 200 open access, online, peer-reviewed journals covering a wide range of academic disciplines. SCIRP serves the worldwide academic communities and contributes to the progress and application of science with its publication.

Other selected journals from SCIRP are listed as below. Submit your manuscript to us via either submit@scirp.org or Online Submission Portal.

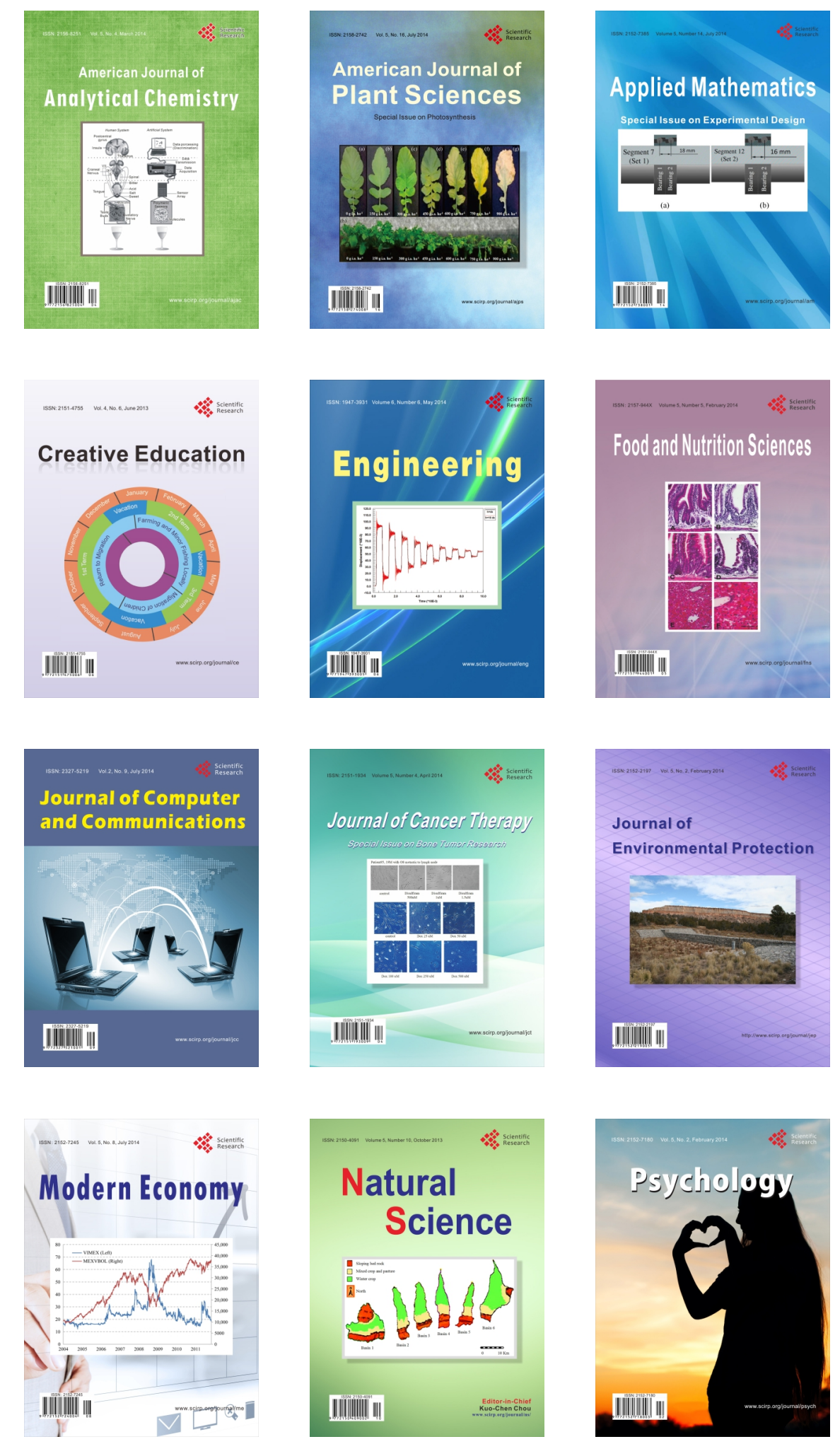